\title{
Review \\ Literature Review of Digital Twins Applications in Construction Workforce Safety
}

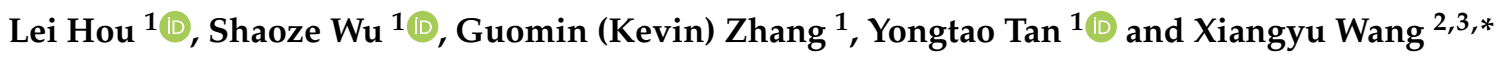 \\ 1 School of Engineering, RMIT University, 124 La Trobe St, Melbourne, VIC 3000, Australia; \\ lei.hou@rmit.edu.au (L.H.); s3767614@student.rmit.edu.au (S.W.); kevin.zhang@rmit.edu.au (G.Z.); \\ yongtao.tan@rmit.edu.au (Y.T.) \\ 2 College of Civil Engineering, Tongji University, Shanghai 200092, China \\ 3 Australasian Joint Research Centre for Building Information Modelling, Curtin University, \\ Perth, WA 6102, Australia \\ * Correspondence: xiangyu.wang@curtin.edu.au
}

check for updates

Citation: Hou, L.; Wu, S.; Zhang, G.; Tan, Y.; Wang, X. Literature Review of Digital Twins Applications in Construction Workforce Safety. Appl. Sci. 2021, 11, 339. https://doi.org/ 10.3390/app11010339

Received: 31 October 2020 Accepted: 22 December 2020 Published: 31 December 2020

Publisher's Note: MDPI stays neutral with regard to jurisdictional clai$\mathrm{ms}$ in published maps and institutional affiliations.

Copyright: (C) 2020 by the authors. Licensee MDPI, Basel, Switzerland. This article is an open access article distributed under the terms and conditions of the Creative Commons Attribution (CC BY) license (https:// creativecommons.org/licenses/by/ $4.0 /)$.
Abstract: For many decades, safety has been a challenge in the construction sector. Despite extensive efforts to improve overall safety, the sector's casualty rate still remains high. In practice, dynamic and complex construction processes may lead to on-site risks and safety plans being overlooked, likely leading to a variety of safety accidents. Nowadays, under the guidance of the digital twins (DT) concept, the advent of state-of-the-art sensing and visualisation technologies has offered the possibility to improve construction health and safety in the workplace. To understand the research advances of these technologies, identify their gaps and challenges, and propose solutions to further advance the industry's safety, we conducted and report a thorough review on the state-of-the-art technological studies, and elaborate upon the key findings in detail. For instance, despite DT being proven to be effective in improving construction workforce safety, the construction industry has yet to fully exploit and streamline these innovations in practice. Overall, this review provides insights into technological clustering, improvement strategies, as well as workforce safety, which can benefit from formulating effective digital technology paradigms.

Keywords: construction workforce safety; sensor; visualisation; digital twins (DT); virtual construction simulation (VCS)

\section{Introduction}

The construction industry has long been plagued by safety issues. According to statistics, there has been no significant reduction in the number of occupational fatalities in major countries or regions over the past five years [1]. According to the China state administration of work safety, 3843 fatalities occurred in China in 2017 [2]. In the U.S., the death toll was 1038 in the construction industry in 2018, accounting for one-fifth of all industry fatalities [3]. The uniqueness and complexity of construction projects make it difficult for the sector to avoid occupational injuries and fatalities [4]. For example, site engineers may lack situational awareness and fail to take measures to identify and prevent imminent hazards.

Digital twins (DT) is a concept of creating a digital replica (the digital twin) of a physical object (the physical twin) and synchronising data from physical twin to digital twin to achieve monitoring, simulating, and optimising the physical object [5]. DT concept was originally applied in the aerospace field [6] and proliferated to other industries with the development of technology. In manufacturing industry in particular, it is not only used to monitor the condition of products, but also to monitor production lines [7,8]. In recent year, the smart building and the smart city gradually adopted the concept of DT to achieve the digital management of the construction products $[9,10]$. At the same time, DT also provides an innovative approach to construction management [11] (Figure 1). 


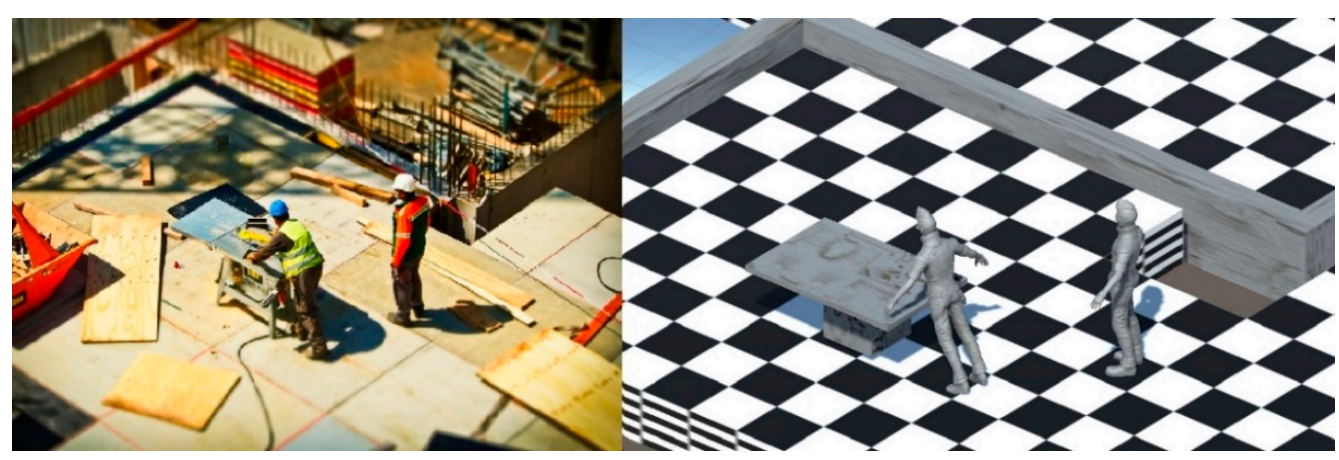

Figure 1. Reflecting the physical elements in the digital twins (DT) environment.

Sensors are a significant underpinning technology component when formulating a typical DT application. There are many types of sensor, including global positioning system (GPS) sensors, radio frequency identification (RFID) sensors, wireless local area network (WLAN) sensors, Bluetooth low-energy (BLE) sensors, ultra-wideband (UWB) sensors, and others [12-17]. Machine learning technology has been well integrated into computer vision to enable object recognition, tracking, and pattern analysis [18,19]. Advanced visualisation technology is helping to improve construction safety as well [20]. The visualisation technology presents dynamic and complex information generated by DT, helping construction managers and on-site workers to make decisions. Building information modelling (BIM) [21], virtual reality (VR) [22-27], and mixed reality (MR) [28-30] are good examples of this. The identification of hazard factors helps guarantee the safe management of all stages of construction. By obtaining relevant data information through BIM, VR, and AR techniques, workers can carry out advance simulations of construction safety management and effectively improve the orderliness and safety of construction activities. Workers can see the danger they are facing and determine the correct mitigation plans to avoid accidents to the greatest extent possible.

Although numerous studies have examined the effectiveness of the DT methodology, a comprehensive, systematic, and evidence-based review is lacking of all individual articles that investigated the effectiveness of using DT in the workforce safety space. For instance, $\mathrm{Li}$ et al. [4] proved that DT can effectively prevent injuries caused by unsafe location-based behaviours, but this would require the support of sensing and tracking technologies such as danger zone identification [16], individual positioning [13], posture estimation [19], semantic analysis [11], and real-time alerts [20]. An examination of this body of evidence with regard to these methodological problems has not been conducted either. Therefore, the objective of this study was to disclose the progress of the current research and determine the relevant gaps, challenges, and future work. CiteSpace was employed to summarise the research trends, advancements, and frontiers of DT applications from 2010 to 2020. Next, an application-focused literature review was conducted, which led to a summary of research gaps, recommendations, and future research directions. Overall, this review provides insight into workforce safety and will help researchers to formulate more effective DT applications that have not yet been sufficiently addressed.

\section{Overview of Construction Workforce Safety}

Accident causation models have been widely introduced to explain the cause of construction safety problems [31,32], revealing that construction environment safety, behaviour safety, and safety awareness are the main factors of risk occurrence. A review of these factors is presented below.

\subsection{Construction Environment Safety}

Construction activities are highly influenced by temporal and spatial conditions [33]. Different spatial locations have different risks. For example, if a worker is on the ground, they need to watch out for vehicles and falling objects, but if they are on the roof, they need 
to worry about falling from a height. The construction workplace is dynamic. Construction involves multiple groups working independently in the same temporal and spatial environment. The progress of all the groups results in constant changes to working environment of the site. A complex and dynamic construction environment is bound to generate a lot of dynamic information. Therefore, construction environmental safety management involves the collection and processing of massive amounts of information.

The management of a construction environment involves all aspects of the site, including the temperature, amount of workspace, and correct setting of safety facilities. Most counties have construction safety regulations. Taking Australia as an example, the Work Health and Safety (Construction Work) Code (2015) [34] requires that the risks of slips and trips caused by surfaces in a workplace be controlled, areas with a risk of falling objects need to be restricted to avoid unauthorised entry, and physical barriers need to be placed around the roadway and fixed parking areas to avoid traffic accident injuries. These regulations summarise the knowledge of previous accidents and help improve the safety of the construction site. However, for complex and dynamic construction sites, the implementation of the regulations is the main challenge as it involves safety planning in the pre-construction stage and construction environment monitoring during the construction stage.

\subsection{Behaviour Safety in Construction}

Workers' unsafe behaviours have been proven to be a major factor leading to accidents $[4,35]$. The management of unsafe behaviours is an important means to reduce occupational casualties. In construction activities, whether workers can behave safely largely depends on their safety knowledge and experience. Therefore, safety training for workers is the standard means to reduce unsafe behaviours. The Australian code [34] requires that general construction induction training, workplace-specific induction training, and other necessary training must be completed before a worker performs a particular construction activity. However, because trainees are different in culture, educational background, knowledge, experience, personality, and preference, their requirements for training are also heterogeneous, so a one-size-fits-all approach to safety training is inefficient. Therefore, researchers have focused on the combination of training and construction activities to supplement the deficiencies of traditional training.

A theory called behaviour-based safety (BBS) was proposed to help improve workers' future behaviour by actively observing and recording their unsafe behaviour and providing feedback to workers [36]. The BBS approach provides workers with a more personalised approach to improving their safety knowledge and experience through observation, feedback, and training. If a worker acts unsafely, it is observed and recorded by a safety inspector, and then reported back to the worker. Specific safety training programs are also developed to reinforce the impression and avoid similar situations in the future. The BBS approach was proven to significantly improve workers' safety performance. Unfortunately, because a large amount of human resources is needed to monitor and provide feedback on unsafe behaviours, BBS is rarely applied in the construction industry. If the identification of unsafe behaviours is accurate enough and the feedback is timely enough, then dangerous behaviours can be stopped in time to avoid accidents.

\subsection{Safety Awareness in Construction}

Similar to behaviour safety, safety awareness is heavily dependent on workers' safety experience. During the construction process, various kinds of interference occur, and the nature of the interference is intrinsically stochastic [37]. Unsafe conditions are inevitable in construction activities, but the risks can be controlled within an acceptable range using appropriate means. Issues related to safety awareness refer to the situation where workers have relevant knowledge and understand the existence of unsafe conditions, but do not take appropriate measures and persist in construction activities. Safety awareness is difficult to measure directly, but it can be reflected in workers' behaviour. For example, 
the situations where a worker works around damaged guardrails, and a worker refuses to equip themselves with personal protective equipment (PPE) when working at heights indicate the workers lack safety awareness. Workers know these behaviours are wrong, but the unsafe behaviours often occur out of a lack of concern for their safety. The reasons for insufficient safety awareness are complex, including personal factors, social influences, environmental conditions, and so on [38]. The most immediate factor is the workers' failure to assess the risks properly. For some low-probability risks, because the accident has not yet happened, people will gradually pay less attention to it. This kind of fluke mentality can have serious consequences when an accident does occur.

The cultivation of safety awareness largely depends on long-term training and practice. In practical projects, workers' safety awareness cannot be permanently improved in a short time. To counter the insufficient vigilance and underestimation of risks, safety signs have been designed and set to provide a warning at the construction site for a temporary increase in safety awareness [39]. The Australian code [34] recommends providing clear instructions at the construction workplace, such as "no entry", "PPE required" and other signs showing hazards. The relationship of the location of signs and the surrounding environment was found to significantly affect the information provision scope of signs [40]. Chen et al. [39] developed an objective measurement paradigm to evaluate the cognitive load of different design features and evaluated the perceptual effects of workers in different attention situations. Based on these findings, visual cues need to consider multiple factors, including location, shape, and colour, to enhance the impact of safety warnings.

Safety signs raise people's safety awareness to a certain extent by providing repeated prompts to people entering dangerous areas, but their limitation is obvious. Static signs are easily obscured by dynamic construction objects. Workers do not have to respond to a safety sign, so a sign will be ignored over time. Portable safety warning approaches, such as ringing or vibration, increase the situational awareness of workers as to when there is a hazardous situation [4]. This kind of real-time reminder can make people pay attention to the environment and reassess the risk in a short period of time, avoiding accidents. However, studies about warning mechanisms aimed at the construction industry remain rare. Large amounts of research are needed to help workers switch their attention from their work to hazards when a sudden danger arises.

\section{Methodology}

Since DT is only a concept, many studies have addressed the concept but did not mention it in the title, keywords, abstract, or even the content of the articles. Therefore, we chose the content-analysis based review method, which has been widely applied in the construction field [41,42]. Three common literature review databases, Scopus, Web of Science, and Google Scholar, were used to exhaustively retrieve articles. As the purpose of this study was to review the application of DT in construction workforce safety, the selection criteria were as follows:

1. The articles should focus on the targeted areas. They should involve construction safety and cover at least one of DT, sensor technology, and visualisation technology.

2. Papers to be reviewed should be journal articles. Compared with other paper types, such as reports, editorials, and conference papers, journal articles are typically peerreviewed and more exhaustive.

3. Journals used for retrieving articles should have significant impacts on the targeted areas and should be indexed in Science Citation Index (SCI), Science Citation Index Expanded (SCI-E), or Engineering Index (EI) databases, which guarantee the professionalism and reliability of articles.

According to the selection criteria, the literature retrieval process is shown in Figure 2. A total of 13 keywords in four categories were selected for an exhaustive search of the required papers (Figure 3). There were two compulsory keywords: construction and safety. Combined with the compulsory keywords, other keywords were used one by one to filter the papers. The selected keywords related to DT were: digital twins, synchronisation, 
and digitisation. The keywords related to sensor technology were selected as sensor, monitoring, positioning, and camera. The selected keywords related to visualisation technology were: visualisation, virtual reality, augmented reality, and mixed reality. At the same time, according to the second criterion, the filter is set to keep only the journal literature. These two steps identified more than 3600 related journal articles.

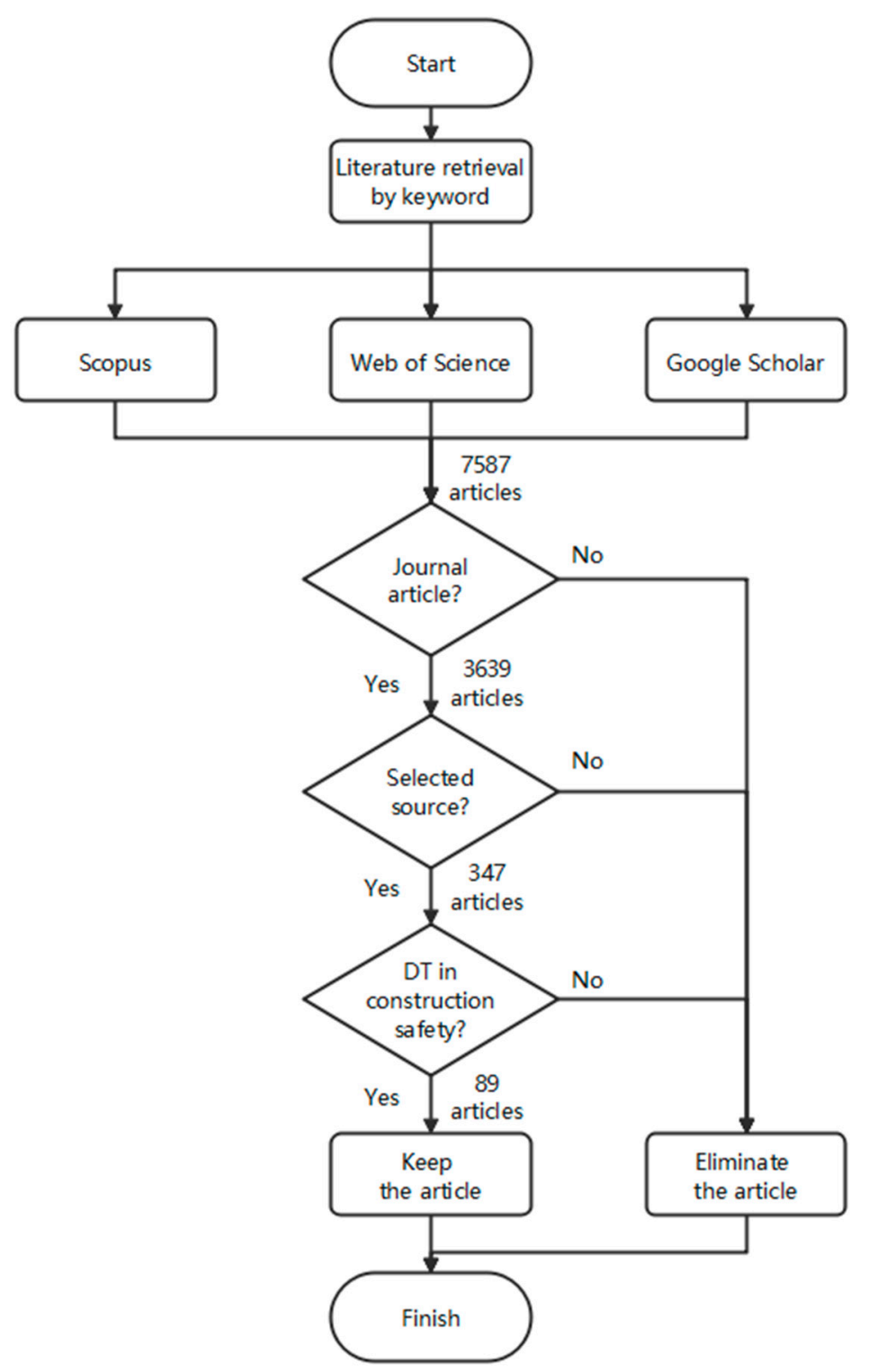

Figure 2. Literature retrieval process.

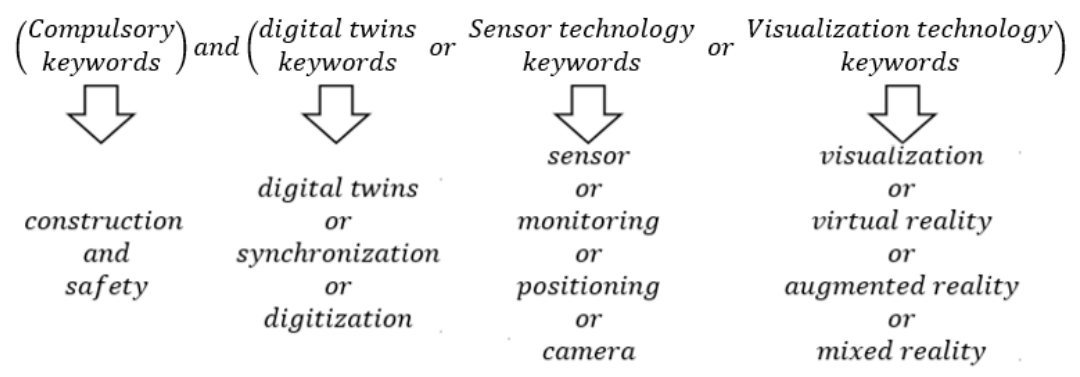

Figure 3. Keywords for the literature retrieval. 
According to the third criterion, the sources of articles are limited to the below-listed journals:

- Automation in Construction (AC);

- Journal of Construction Engineering and Management (JCEM);

- $\quad$ Safety Science (SS);

- Journal of Computing in Civil Engineering (JCCE);

- Advanced Engineering Informatics (AEI);

- Journal of Information Technology in Construction (JITC);

- Accident Analysis and Prevention (AAP);

- Journal of Engineering, Design and Technology (JEDT);

- Applied Ergonomics (AE);

- Journal of Performance of Constructed Facilities (JPCF).

At this point, automatic filtering reduces the number of articles to 347. After a visual examination of the content of the article, 256 articles were excluded due to lack of relevance. In total 89 articles were obtained for further analysis. The retrieval approach may not comprehensively cover the articles related to the application of DT in construction workforce safety; however, this method was sufficient to provide a significant number of state-of-the-art research works, from which this review could generalise findings and recommend future works.

\section{Demographics of Articles}

The quantity of articles has grown over time. The number of yearly publications remained below 4 from 2010 to 2014, between 7 and 11 since 2015-2018, and skyrocketed from 11 to 23 up until 2020 (Figure 4). Considering that this article was written in the middle of 2020, the actual number of articles should be much higher. Figure 5 shows the number of articles published in the selected journals. AC has 43 papers, nearly half of the total publication number. Compared to $\mathrm{AC}$, other journals have fewer publications, i.e., 15 for JCEM, 8 for SS, 8 for JCCE, 6 for AEI, 3 for JITC, 2 for AAP, 2 for JEDT, 1 for AE, and 1 for JPCF.

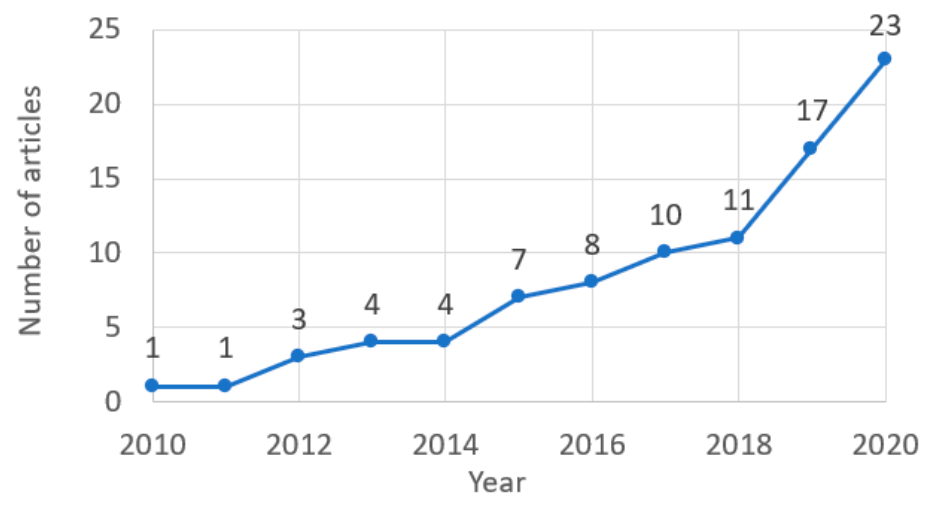

Figure 4. Number of articles distributed in different years.

Through the content analysis of the reviewed articles, the research of DT has two major branches. The first uses sensor technology to collect and process real-time information. The other one combines the processed information with a virtual construction site to simulate and visualise construction activities. The research of sensor technology in construction safety can be divided into three sub-branches, namely, identification of unsafe construction environments, on-site individual positioning, and workforce behaviour monitoring. Virtual construction simulation and visualisation provide three application branches for DT, namely, safety planning, construction activity visualisation, and safety training. The numbers of articles in different sub-branches are shown in Table 1, and the findings are described in Sections 5 and 6. 


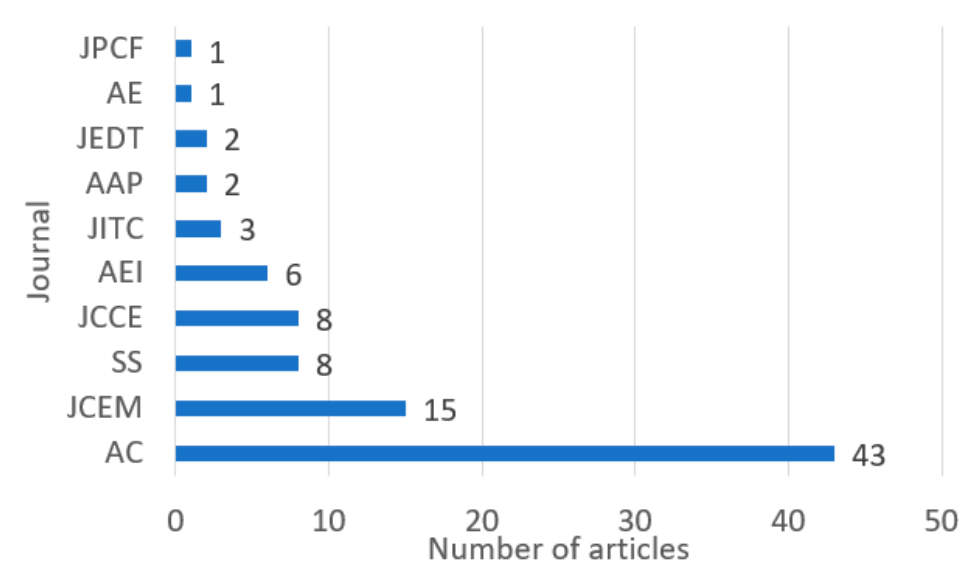

Figure 5. Number of articles published in the selected journals.

Table 1. Number of articles in different research branches.

\begin{tabular}{ccc}
\hline Research Branches & Sub-Branches & Number of Articles \\
\hline \multirow{2}{*}{$\begin{array}{c}\text { Sensor technology in } \\
\text { construction safety }\end{array}$} & Identification of unsafe & 14 \\
& Construction environment & 16 \\
& On-site individual positioning & 13 \\
\hline Virtual construction simulation & Safety planning & 16 \\
and visualisation technology & Construction activity & 20 \\
& visualisation & 12 \\
\hline
\end{tabular}

\section{Sensor Technology in Construction Safety}

The data transmitted by sensors can either carry straightforward information such as coordinates, speed, angle, rotation speed, force, and temperature, or complex information such as sound, images, and videos. Complex information contains large amounts of hidden information, such as the relative position and movement, which can be extracted through some technology methods. Therefore, a literature review about sensor research should focus on both the information being extracted and the methods used to extract it. Among extraction methods, the most popular is based on computer vision. Computer vision is an interdisciplinary research field focusing on extracting information from the real world through images or videos. Through the acquisition, processing, and analysis of digital images, users are provided with the hidden information they need. In the field of construction safety, computer vision has been used to examine specific situations of the construction stage, such as tracking the location of on-site individuals, behaviour monitoring, and PPE checking. The application of sensors in construction safety effectively increases the automation degree of construction monitoring, which significantly reduces repetitive labour and increases work efficiency. The real-time data provided by the sensor also provide the information foundation for DT.

\subsection{Identification of Unsafe Construction Environment}

The occurrence of unsafe conditions is unavoidable in the construction site. The challenge is to identify and deal with the unsafe condition in a timely manner. Given the variety of conditions that may occur during dynamic construction activities, such as scaffolding damage, loss of guardrails, and movement of heavy equipment, ensuring that every unsafe condition is detected before the occurrence of an accident relies heavily on human efforts, which are limited on-site. Therefore, sensor technology can be used to automatically monitor the construction environment. Cho et al. [43] developed a system to estimate the status of scaffoldings, including safe, over-turning, uneven settlement, and over-loading, by fitting strain sensors onto the scaffoldings. They developed a model to distinguish different 
safety conditions of scaffolds through the combination of finite element analysis (FEA) and machine learning. The system has the potential to estimate the status of reinforced concrete structures by introducing material performance [44] and structural behaviour [45]. The dynamic model is able to accurately reflect the real situation [46]. Another monitoring method based on transfer learning and a convolutional neural network (CNN) was developed by Kolar et al. [47]. The method detects the installation of safety guardrails through the 2D image captured by a camera, which has the potential to ensure the effective implementation of a safety plan. Heavy equipment moving around the construction site, including excavators, also pose a hazard area to those in the surrounding area. Song et al. [48] proposed a spatial prediction method to assess traffic issues. Soltani et al. [49] combined the images captured by multiple cameras at the construction site to form stereo vision to estimate the $3 \mathrm{D}$ pose of the excavator. The researchers digitised the situation of a physical twin to a digital twin. Through the analysis of the digital twin, human-readable information is extracted from a vast amount of abstract data, which eliminates the complicated manual processing, and effectively and reflects the monitoring content of the construction environment in a timely way.

With the help of workers' safety experience and behaviour, some methods have been proposed to identify unpredictable, dangerous situations and hazard areas to fill the gap between the safety plan and the real construction situation. Kim et al. [50] developed a method for automatic identification of hazardous areas by monitoring workers' movements. They compared the optimal route with the route chosen by workers to determine the areas where they refuse to enter. With the help of the algorithm, these areas can be analysed to determine whether there is a hazard. Another method involves collecting workers' gait abnormalities by having them wear inertial measurement unit sensors (IMUs) around their ankles. The gait abnormalities were found to be strongly correlated with the presence of hazards, such as slippery floors and uneven floors [51]. Kim et al. [52] introduced fuzzy inference to judge the safety level of everyone on a construction site at any given moment by extracting spatial information about on-site entities, including individuals and equipment.

\subsection{On-Site Individual Positioning}

Even if a hazard area can be displayed for managers, it is still difficult to determine whether people are entering the hazardous area [53]. Because occupational risk only exists when the workforce is present, monitoring the position of on-site individuals becomes particularly important. At present, two kinds of mainstream positioning method are being used. One is the sensor-based positioning methods, including wireless networks, RFID, UWB, and GPS. He and Peansupap [54] used GPS to locate an outdoor individual and an object being hoisted by a crane to warn the individual who was about to step into the danger area under the object, avoiding falling injuries. The other kind is vision-based positioning, which is based on computer vision technology [55]. Vision-based positioning method relies on cameras to obtain images or videos. Then, computer vision algorithms are used to identify and track on-site individuals or other objects [56,57]. The on-site position can be digitised by mapping the object in images/videos to the actual location (Figure 6). Combined with individual positioning and the aforementioned construction environment monitoring, DT has made remarkable contributions to avoiding collisions. The method has been proven to be useful for detecting collision hazards between individuals and vehicles [58] and between individuals and heavy machinery [59]. By installing cameras around equipment, equipment operators can obtain the location information of surrounding workers and avoid collisions. 


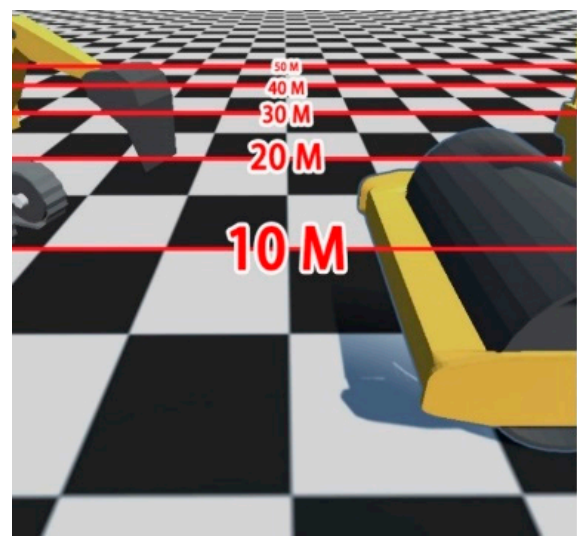

(a)

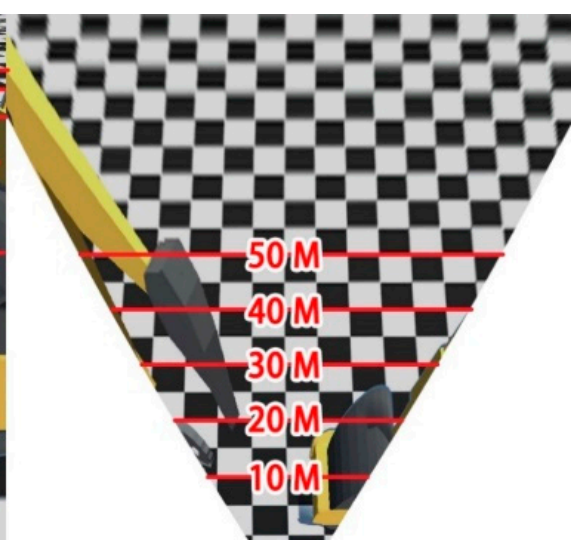

(b)

Figure 6. Mapping the object in images to the actual location (a) before and (b) after projective transformation.

\subsection{Workforce Behaviour Monitoring}

In most cases, the worker's actions are the direct cause of the accident [60], and the identification and prevention of unsafe acts can avoid most of the casualties. Therefore, the digitisation of workers cannot stop at positioning. A digital twin needs to synchronise the behaviour of its physical twin, which results in motion monitoring being crucial. The mainstream method used for automatic action monitoring is extracting the 3D skeleton from images or videos [61]. By comparing the motion of the skeleton with pre-set motion templates, unsafe behaviours can be identified in real-time. The use of 3D cameras has been proven to be accurate and timely for detecting unsafe behaviour in climbing ladders [62] and traversing structural supports [63].

In addition to the action of workers, a large number of construction injuries are caused by inadequate use of PPE [64]. Based on support vector machine (SVM), Park et al. [65] developed a method to determine the spatial positions of workers and hard hats through images captured by on-site cameras. By matching the geometric and spatial relationships between the workers and hard hats, individuals without a hard hat can be automatically identified. In terms of working at height, harnesses and anchoring are prescribed as necessities, but people still violate the rules. Fang et al. [66] and Fang et al. [67] detected the implementation of safety prevention measures during aerial work with $\mathrm{CNN}$ and regions with $\mathrm{CNN}$ ( $\mathrm{R}-\mathrm{CNN}$ ). These deep learning algorithms provide an innovative method to extract hidden information from data, facilitating the realisation of the DT concept. The automated detection method proposed by researchers not only reduces labour costs but also improves the scope and accuracy of incorrect PPE usage to assist managers during safety inspections.

Other forms of unsafe behaviour, such as working under the influence of alcohol or under high fatigue, also negatively affect construction safety as they are mainly manifested in physiological status. Therefore, the use of sensors for physiological condition monitoring was studied [68]. Balance detection tools integrated with IMUs and fuzzy set theory have been developed to detect the balance performance of workers [69]. Hwang et al. [70] and Jebelli et al. [71] introduced an electroencephalogram (EEG) to monitor the stress levels of workers. These monitoring methods provide more detailed data for digital replicas of workers so that a digital twin is able to accurately simulate the physical twin.

\section{Virtual Construction Simulation and Visualization Technology}

In the construction stage, monitoring approaches, like virtual construction simulation (VCS) collect large amounts of dynamic safety information from the construction site, which can be transferred to a digital replica to simulate the construction activity. In addition to the real-time safety information, VCS requires the support of BIM and a 
knowledge base to complete the simulation of construction activities. Visualisation technology provides human-computer interaction interfaces to help construction officers access the VCS to comprehensively understand the construction situation. The combination of visualisation technology and gamification has been introduced into construction safety. With the emergence of new hardware (HTC Vive, Oculus Rift, Microsoft HoloLens, etc.), VR, MR, and augmented reality (AR) have become hot research areas in recent years [72]. The new hardware provides more choices for the application of visualisation technology. VCS and visualisation technology provide output ports for DT, which allows users to access digital replicas to deepen their understanding of the construction safety situation, further proactively address construction safety issues, and optimise the construction activities.

\subsection{Safety Planning}

In the pre-construction stage, there is no physical twin, so there is no DT. However, information and communication technology (ICT) is used throughout the whole life cycle of buildings, so the BIM being created in the pre-construction stage can continue to be used during the construction stage, providing an information basis for DT. Complete safety planning provides various emergency plans, which also provide a knowledge base for computers to understand and solve construction safety issues. Therefore, the study of DT cannot ignore construction safety planning. Through science mapping, BIM has been widely used in visualisation to solve construction safety issues, including hazard recognition and prevention [73]. Through the rendering of 3D buildings, visualisation technology provides stakeholders with a more intuitive construction safety plan. A 4-dimensional (4D) BIM model contains construction details, including geometry models, schedules, and construction activities, which helps safety officers to intuitively identify potential safety problems compared with traditional 2D drawings and schedules. Risk levels can be visually presented in different colours on 3D models for hazardous area identification and risk assessment [74,75]. With the aid of BIM, on-site hazard areas and hazard types can be effectively determined, and a foundation can be laid for safety management in the construction stage [20].

Based on abundant safety information, researchers established logic-based mapping from human language to machine-readable form, which makes safety regulations and safety knowledge understandable for BIM software. By mapping engineering information and safety rules in BIM, hazards can be automatically identified and handled during both the pre-construction and construction stages. A BIM-based safety rule checking system was developed to automatically identify locations of hazardous areas and recommend the corresponding protection measures [76]. By comparing the BIM with safety rules, safety issues can be summarised. The countermeasures from the rules can also be presented, which helps safety officers make decisions. Getuli et al. [77] further strengthen the system by adding temporary structures and heavy equipment such as scaffolding and a tower crane to the system, increasing its robustness. These rule-checking systems can not only be used to refine safety plans but also to check construction activities in real-time, providing an innovative approach for hazard identification and resolution in DT.

\subsection{Construction Activity Visualisation}

The monitoring described in Section 5 is able to provide massive amounts of dynamic information for construction management. The huge amount of information enables the safety officers to have a more comprehensive understanding of the construction situation, but increases their workload and mental load to process the information for decision making. Only after the synchronised data are processed and delivered to specific users can construction safety be improved. A VCS system was proposed to process the data collected from safety planning and construction. Zhou et al. [53] developed a prototype to analyse and visualise the risk of a workplace based on field-monitoring data and 4D BIM-based safety planning, which provides safety officers with timely information to make decisions regarding construction safety issues. VCS is also expected to offer solutions 
automatically. To address the limitations of safety knowledge, ontology was used to model safety knowledge and semantic information [78]. By building an ontology model, a complete knowledge base can be built. The knowledge base includes hazards, precursors of the hazards, and solutions to deal with the hazards [79]. When precursors are outside the acceptance criteria, the situation is identified as a hazard, and corresponding solutions are automatically generated to solve the hazard. With the aid of ontology, the response of structural members in different loads, such as seismic loads [80,81], blast loads [82,83], and impact loads $[84,85]$, has the opportunity to be integrated, which can provide the knowledge basis for accident simulation.

A proactive construction management system (PCMS) developed by Li et al. [86] combined a real-time location system (RTLS) and a VCS system. The RTLS can locate workers, equipment, vehicles, and other moving objects and transmit their position to the VCS system. The VCS system simulates the 3D construction workplace with hazard zones. The coordinates of identified construction equipment and workers are translated and visualised in the VCS system. Once a worker approaches a hazard zone, a process is triggered to report the situation and warn the worker. Similarly, many studies have focused on the visualisation of workers' locations [87] and behaviours [61,62] in virtual construction sites, helping safety officers to quickly determine the workers' locations and unsafe situations to manage the emergency. VCS integrates BIM, ICT, and ontology into construction safety management, increasing the digitisation and automation of hazard identification and prevention.

Warning mechanisms are used to keep workers away from hazardous zones. Vibration and sound are commonly used to deliver warnings to on-site individuals without interrupting their work [8], which is effective in deterring workers from taking risks. Innovative visualisation technology has been introduced to avoid accidents for on-site individuals. For example, for equipment operators and drivers, real-time images displaying the location of surrounding workers and facilities can effectively reduce strike accidents caused by blind spots $[59,88]$. Talmaki et al. [89] presented pipeline information through AR using a cabin monitor to prevent an on-site individual from safety issues. A wearable hazard avoidance AR system was developed by Kim et al. [58]. They visualised the direction, distance, and the degree of danger of a vehicle nearest to its user through a coloured arrow with a safety level indicator. The system provides a new method to avoid accidents by integrating on-site safety warnings and a head-mounted display (HMD). By overlapping a virtual environment on the real world, the view provided by AR or MR HMD fits better with the human visual mode than conventional displays. Considering the dynamic nature of a construction site, the introduction of HMD solves the problem of the time lag between the action and notification in the traditional on-site warning method.

\subsection{Safety Training}

DT also focuses on the optimisation of physical entities. In addition to the optimisation of the construction site, the improvement of the workers is essential, which is mainly reflected in safety training. Based on the analysis of the performance of a digital twin, knowledge gaps can be identified. Conducting targeted training for problems that arise during work can help to efficiently upskill the construction workforce. The PCMS [86] mentioned above is able to improve safety training programs while judging on-site individuals' risky behaviours. The system identifies and records the unsafe behaviour of a worker during the construction activity. Then, targeted training is provided for the enhancement of the worker's safety knowledge and awareness [4]. However, traditional safety training still has some weaknesses, such as failure to stimulate interest in learning and lack of hands-on practice. Although on-the-job training has been proven to be more efficacious [90], it cannot be widely used because it is time-intensive, expensive, and potentially hazardous [91].

The integration of game technology and visualisation technology emphasises interaction in the development. It provides an innovative training method that can replace on-the-job training to some extent. Visualisation technology creates a virtual construc- 
tion environment that allows users to walk, observe, and interact with virtual objects. By generating various scenarios of real construction activities being synchronised in VCS in a virtual environment and allowing users to judge whether they conform to safety regulations, the safety knowledge and awareness of the workers can be accurately and objectively evaluated [92]. Using a mouse, keyboard, controller, and other devices, trainees can perform construction activities, such as installation, operating, and dismantling, in a virtual environment to improve their professional skills [93].

VR has also been introduced for safety training. The immersive experience provided by VR allows trainees to perform the same operation as in reality and obtain visual, auditory, and tactile feedback [94]. Le et al. [95] created an online VR system framework, proving that trainees can learn safety knowledge effectively through role-playing, dialogic learning, and social interaction in a VR environment. More importantly, VR does not present the hazards of on-the-job training. It allows workers to make wrong decisions in the VR environment and know the consequences of the decision [27]. By observing unsafe behaviour and its negative consequences, individuals will avoid performing similar behaviours [96]. This kind of training provides game-like experience, which can fully mobilise the enthusiasm of trainees, thereby improving training efficiency and the effect of knowledge transfer [97].

\section{Discussion}

As mentioned in Section 2, the root cause of construction safety issues can be divided into three categories: construction environment safety, behaviour safety, and safety awareness. The existing studies have made contributions to solve the safety issues from different aspects, as described in Sections 5 and 6. Based on the content analysis of the reviewed articles, a comprehensive, systematic, and evidence-based summary is presented in this section. The summary provides an intuitive way to describe the contributions of state-of-art research results to different safety issues and the relationships among various research areas (Figure 7). Moreover, it reveals the current challenges and future work to improve the construction workforce safety through DT.

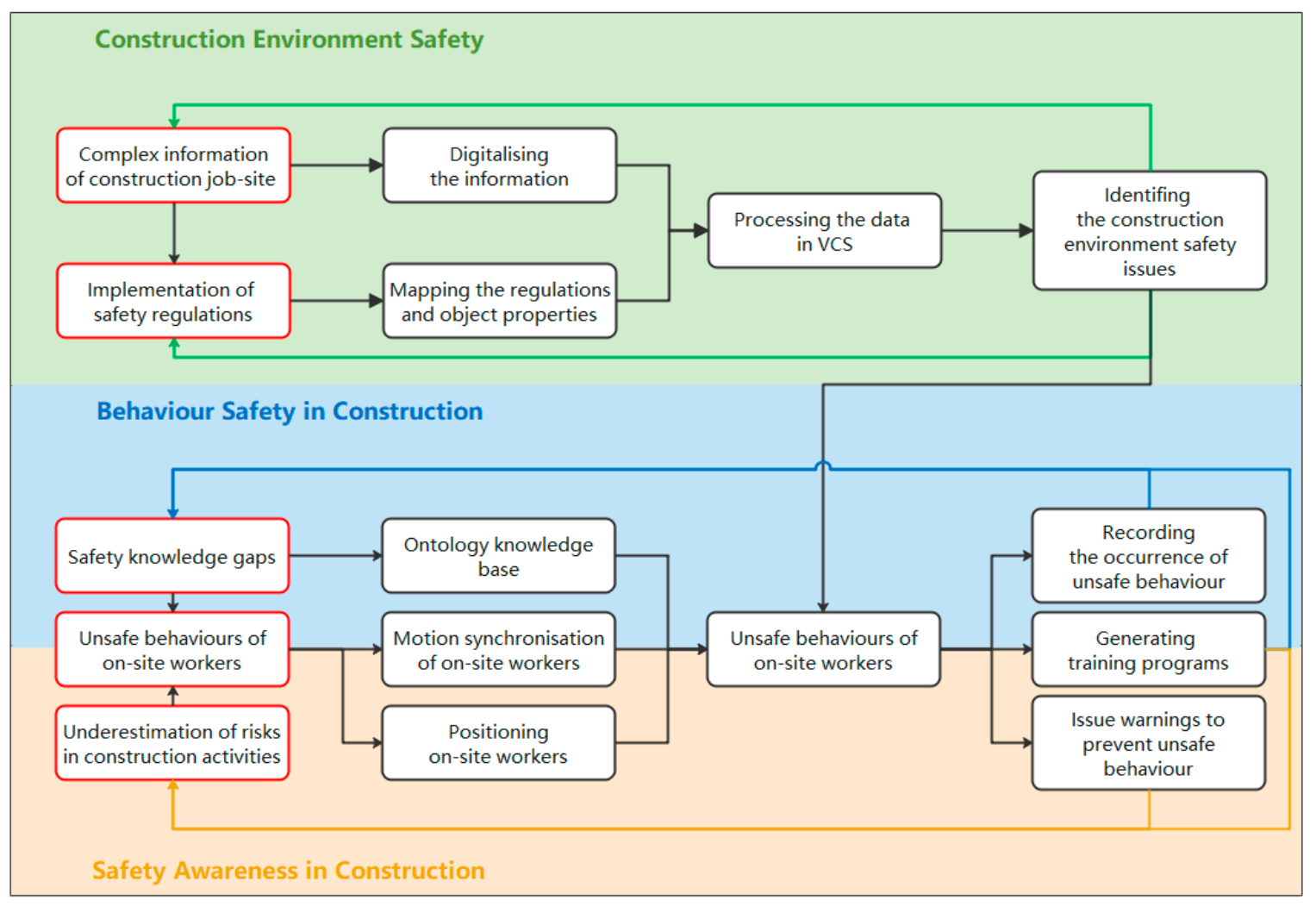

Figure 7. The approaches used in the existing research to improve construction workforce safety. 


\subsection{The Status Quo of Digital Twins (DT) to Improve Construction Workforce Safety}

The main problem in the construction environment safety category is that useful safety information in complex construction environments is mixed with useless information, which is difficult to distinguish for both construction managers and on-site workers. This also complicates the proper implementation of safety regulations for the construction environment. These problems are widespread in construction projects, and the following solutions are proposed based on the DT concept. 4D BIM and sensors can be used to digitise the construction site $[43,46,49]$. The $4 \mathrm{D}$ BIM simulates the construction activity, and the sensors synchronise real-time data during construction to monitor unexpected events. Therefore, a digital twin of the construction environment can be generated to virtually simulate the construction environment $[53,86]$. Through natural language processing, the content of safety regulations can be mapped to the properties of objects in the construction site item by item [76-78]. By analysing the digital replica, a script automatically checks the BIM based on regulations to identify the construction environment safety problems. This process extracts hidden information from a large amount of data and plans and checks the safety regulations.

The categories of behaviour safety and safety awareness are related to on-site workers. Only when workers have sufficient experience and knowledge and correctly estimate the risks in construction activities can they act safely [60]. Therefore, the solution to this problem should focus on both the long-term improvement in workers' quality and the timely prevention of unsafe behaviours in the short term. Firstly, construction knowledge based on articles, manuals, and experience should be summarised to generate a knowledge base $[78,79]$. With the help of ontology, connections between knowledge and physical entities can be established to describe the behaviours of workers that could lead to accidents under certain circumstances. In terms of the behaviour of workers, the current research has two main branches: the location and the motion information of workers. In both cases, digital replicas are created to synchronise physical entities. The study of digital replicas not only avoids the interference of construction activities [4] but also reasonably removes redundant information [62], which confirms the important role of the DT concept in construction workforce safety. Together with the digital twin of the construction environment, the synchronisation with the worker achieves the fundamental DT concept in construction. By integrating and analysing the position, equipment, and behaviour of workers, the relationships among them are matched with the relationships described in the ontology knowledge base. Therefore, (1) the occurrence of risky behaviours can be documented to supplement knowledge gaps, (2) training programs can be customised based on unsafe behaviour to improve workforce quality, and (3) real-time warnings can be triggered to stop unsafe behaviour in time, thus directly avoiding accidents.

\subsection{Challenges and Future Works}

The application of the DT concept has the potential to improve workforce safety. However, further development is required before the concept can be fully applied in construction practice. Many gaps and challenges remain to be solved in the field of construction workforce safety.

\subsubsection{Sensor-Based Indoor Positioning}

The first step in the realisation of the DT concept is the synchronisation of construction activity information; the first step in the synchronisation of construction activity is the synchronisation of spatial positions. However, both sensor- and vision-based positioning are still limited. Trilateration, triangulation and scene analysis are the basic principles of sensor-based positioning, which are formed based on the characteristics of signal transmission [98]. The former two principles use the time difference and phase difference generated in the signal transmission at different positions. With construction activities, these two principals have always been used in an outdoor environment with no shielding. However, it has rarely been used in indoor environments because they are inaccurate when the signal 
is blocked or interference occurs. Scene analysis, also known as fingerprinting, is considered the most feasible method for indoor positioning [54]. This method determines the location of the target in the space by comparing the characteristics of the positioning signal data with the recorded environmental signal data. However, as the signal characteristics constantly change during the construction activities, considerable human effort is required to update the environment signal characteristics, so the method has rarely been used to locate an on-site individual during the construction stage. The current solution to deal with sensor-based indoor positioning is increasing the number of signal base stations to reduce the impact of walls and floors on signals. This is expensive and labour-intensive.

\subsubsection{Mapping between Videos and the Real Construction Site}

Vision-based positioning is in the early stage for application to construction safety. Researchers need to increase their effort into tackling the challenges, including occlusion, clutter, illumination, and scale variation [99]. However, the critical challenge faced by the implementation of vision-based positioning is mapping video being captured by a camera and the actual location of the construction site. Several of the reviewed studies used machine learning to collect information from images to determine the location of a worker or an object. However, unlike a sensor that can directly obtain the exact position, image-based positioning only provides a relative position. This position is the coordinate relative to a point (upper left corner) of the screen rather than the actual location of the object on the construction site, so it is impossible to estimate the danger outside the field of vision. Therefore, the information from image-based positioning needs further data processing for the synchronisation with construction activities.

There are three issues for information processing. The first is mapping the local coordinates in the video with the actual position of the workplace. Existing studies have simplified the construction site into a plane to map the local coordinates and the actual location. However, many slopes and pits exist on a construction site, so it is necessary to synchronise the complex terrain on the site first, and then establish the mapping between the coordinate in the video and the position in the real world. The second issue is that the terrain of the site changes gradually as construction progresses. The synchronisation of the terrain should also be updated as the project progresses. The last issue is the integration of object positioning information. When multiple cameras capture the same object at the same time, an object detection algorithm recognises the object separately from each video, providing duplicate information. In a VCS, however, the algorithms need to accurately determine that there is only one object at that location. These three issues involve multi-disciplinary fields such as 4D BIM, lens distortion, object detection, vibration control, topology, and stochastic degradation $[74,89,100-102]$. A wider range of knowledge is needed to break through the current bottleneck.

Future works dealing with the positioning issues are most likely to introduce simultaneous localisation and mapping (SLAM). SLAM was originally used to solve the localisation, navigation, and mapping construction problems of mobile robots running in an unknown environment. For constantly changing construction sites, workers can use SLAM to automatically update the environment on the construction site in real-time. Regarding the devices, many electrical devices such as mobile phones and AR HMD already have time of flight (ToF) or light detection and ranging (LiDAR) modules, which form the hardware base of SLAM. The introduction of SLAM would mitigate the former two issues. Therefore, the third issue will become the bottleneck.

\subsubsection{Information Processing}

DT, in the field of construction safety, allow users to understand the actual construction activities with the help of a digital replicate. Information processing is the main aspect of DT technology, which aims to solve how to identify and deal with hazards from synchronised construction activities. Adequate safety knowledge is necessary if an inspector wants to identify hazards. Similarly, for automatic identification of hazards, adequate 
machine-understandable safety knowledge is necessary for a VCS. Previous studies have tested automatic hazards identification for only a few dangerous situations. For complex construction sites with all kinds of hazard, the rule checking is inevitably slow, causing considerable delays. Therefore, it is necessary to optimise the rule checking algorithm, such as optimising the inspection sequence and skipping redundant inspection items. VCSs mostly use BIM as an information base to extract the required construction information or geometric models to achieve corresponding functions. However, for the massive amount of BIM information in a project, information retrieval and export consume large amounts of computing power [103]. In the steps of model transformation, information is lost [104]. These findings reveal that BIM's interoperability still has room for improvement.

When recommendations to deal with the identified risks are proposed by a VCS, conflicts or new dangers may arise. For example, if there are two adjacent holes in the floor, the rule-checking system may recommend covering them with two separate planks, but the placement of the two planks would overlap, which is a conflict. Deeper logical relationships between rules should be studied to make the recommendations more robust. In future research, ontology should be developed to model the logical relationships between rules, describing in detail the relationships among workers, objects, and hazards, forming a digital knowledge network. The collected real-time construction activity information should be connected with the knowledge network from the perspective of semantics, which has the potential to improve the speed and accuracy of hazard identification. The application of ontology will also provide safety guidance for the application of new technologies in construction, including automatic driving [105] and 3D printing [106].

To develop a knowledge network, rules, manuals, articles, and meetings are the primary means of sharing knowledge. However, in addition to the explicit knowledge that can be clearly expressed and effectively transferred, the sharing of tacit knowledge is crucial [107]. The tacit knowledge hidden in worker behaviour and construction data needs further research to be extracted. The retrospection and reflection on near-miss accidents can effectively avoid the occurrence of future injury accidents. Through a real-time tracking system [108] and heat map [109], near-miss accidents can be recorded in detail. Therefore, another potential research direction is to enhance the learning ability of VCSs, integrating knowledge acquired from near-miss accidents into the knowledge networks to extend the knowledge network.

\subsubsection{Warning Mechanisms}

The purpose of the practical application of DT in construction safety is to simplify complex construction sites and display construction safety information, including hazardous areas, worker behaviour, and emergencies, to help safety officials and workers make quick decisions and avoid accidents. The method of transmitting real-time safety information to off-site security officers is mature, whereas the research on transmitting safety information to an on-site individual is still in an early stage.

Workers exposed to danger are the last defender against accidents. However, in a disorderly construction site filled with invalid visual and auditory information, incorrect decisions can be made due to workers being unable to distinguish useful from useless information. Even if a worker succeeds in obtaining the safety information related to a hazard, they need to recognise the hazards revealed by the information. Later, to ensure their own safety, the worker needs to perceive responses and choose a safety response. Finally, only if this safety response is properly executed can workers avoid accidents [110]. Several cognitive analysis models describe this process, revealing that it involves human factors such as attention, safety awareness, safety knowledge, memory retrieval, and safety attitudes [60,111,112]. Under normal circumstances, workers are competent enough to complete the cognitive process correctly and avoid accidents. However, unsafe behaviour still occurs from time to time during construction activities due to negligence and a lack of vigilance [112]. The provision of warnings is an important approach to help on-site workers avoid accidents by providing workers with useful safety information about the 
surrounding workplace. However, the mechanisms through which warnings can affect workers' behaviour through cognitive processes are unclear, such as which step in the cognitive process is affected by the safety information provided and what information is helpful to prevent accidents. Therefore, the design and evaluation of warning mechanisms have been hampered.

With the help of automated monitoring technology, hazardous areas and unsafe behaviours can be identified in real-time. A warning approach was proposed: when an on-site worker approaches a hazardous area or acts unsafely, a device on their helmet warns them with a sound [4], which allows workers to understand the existence of the hazard. However, it fails to help the worker identify the hazards in the surrounding workplace for active decision making. MR and AR visualization technology have been widely studied for collaboration [113], operation [114,115], maintenance [116,117], and inspection [15,118]. They are advantageous in displaying context-aware safety information [58]. However, too much information may block the view of the users to some extent, and workers need to spend time and attention reading the extra safety information, causing distraction. Therefore, effectively conveying safety information to workers through technical approaches to achieve the purpose of warning needs to be explored.

\subsubsection{Workforce Upskilling}

Another challenge is personalised training. There is a proclivity for improving existing methods such as BBS, neglecting the root cause of unsafe behaviour, and ignoring issues regarding values and attitudes [119]. The challenge is that the current research about safety training lacks a personalised analysis of the characteristics of individuals. For a single project, a digital twin for each individual worker can provide a history of their behaviour. Then, a worker profile can be generated to evaluate the values and attitudes for bettercustomised training. The profile is a potential research direction for personalised training. This future work should involve behaviour patterns, worker privacy, and the design of training programs.

\section{Conclusions}

The DT concept, combined with sensor technology and visualisation technology, provides the capability to automatically synchronise construction activities and, therefore, can be used to improve construction workforce safety. Although many researchers did not mention the term digital twins in their papers, they introduced the concept of DT into their research. In this paper, articles in the field of construction safety involving sensor and visualisation technologies were reviewed to describe the state-of-the-art research outcomes. Several challenges need to be addressed before the field of construction workforce safety can directly benefit from DT. The review was conducted to identify the challenges by examining the use of sensor technology and visualisation technology. The main challenges have been generated by the dynamic and complex nature of construction activities and the immaturity of information synchronisation and processing. More specifically, (1) appropriate methods are lacking to synchronise complex and dynamic construction information. Sensors can only track specific objects and are costly for changing indoor environments. Synchronisation schemes based on cameras are extensible to capture all possible hazards, but mapping the captured objects with the location of a changing workplace is difficult. (2) The processing of information is limited when dealing with the complex logical relationships among objects, hazards, and safety rules. (3) The mechanism through which safety information should be provided to on-site workers through technical means to provide safety warnings is unclear. Based on the challenges, future research efforts should be directed toward: (1) SLAM technology to achieve the dynamic synchronisation of the construction workplace; (2) ontology to model the relationship among objects, hazards, and safety rules; and (3) the mechanisms through which warnings can affect workers' behaviour through cognitive processes. 
Author Contributions: L.H., S.W., G.Z., Y.T. and X.W. contribute to literature retrieval, literature classification, and generalisation of major knowledge. L.H. and S.W. wrote the paper. All authors have read and agreed to the published version of the manuscript.

Funding: This research received no external funding.

Acknowledgments: The authors would like to acknowledge KAEFER Integrated Services for their sponsorship of this study.

Conflicts of Interest: The authors declare no conflict of interest.

\section{References}

1. Fang, D.; Huang, Y.; Guo, H.; Lim, H.W. LCB approach for construction safety. Saf. Sci. 2020, 128, 104761. [CrossRef]

2. China State Administration of Work Safety (Work Safety Summary in 2017). Available online: http://www.chinasafety.gov.cn/ newpage/aqfx/aqfx.htm (accessed on 6 April 2018).

3. Occupational Injuries and Illnesses and Fatal Injuries Profiles; U.S. Bureau of Labor Statistics: Washington, DC, USA, 2018.

4. Li, H.; Lu, M.; Hsu, S.-C.; Gray, M.; Huang, T. Proactive behavior-based safety management for construction safety improvement. Saf. Sci. 2015, 75, 107-117. [CrossRef]

5. Batty, M. Digital twins. Environ. Plan. B Urban Anal. City Sci. 2018, 45, 817-820. [CrossRef]

6. Tuegel, E.J.; Ingraffea, A.R.; Eason, T.G.; Spottswood, S.M. Reengineering Aircraft Structural Life Prediction Using a Digital Twin. Int. J. Aerosp. Eng. 2011, 2011, 154798. [CrossRef]

7. Boschert, S.; Rosen, R. Digital Twin-The Simulation Aspect. In Mechatronic Futures; Springer: Cham, Switzerland, 2016.

8. Schleich, B.; Anwer, N.; Mathieu, L.; Wartzack, S. Shaping the digital twin for design and production engineering. Cirp Ann. Manuf. Technol. 2017, 66, 141-144. [CrossRef]

9. Howell, S.; Rezgui, Y. Beyond BIM, Knowledge Management for a Smarter Built Environment; BRE Electronic Publications: Berkshire, UK, 2018.

10. Mohammadi, N.; Taylor, J.E. Smart city digital twins. In Proceedings of the 2017 IEEE Symposium Series on Computational Intelligence (SSCI), Honolulu, HI, USA, 27 November-1 December 2017.

11. Boje, C.; Guerriero, A.; Kubicki, S.; Rezgui, Y. Towards a semantic Construction Digital Twin: Directions for future research. Autom. Constr. 2020, 114, 103179. [CrossRef]

12. Arslan, M.; Cruz, C.; Roxin, A.M.; Ginhac, D. Spatio-temporal analysis of trajectories for safer construction sites. Smart Sustain. Built Environ. 2018, 7, 80-100. [CrossRef]

13. Lee, H.S.; Lee, K.P.; Park, M.; Baek, Y.; Lee, S.H. RFID-Based Real-Time Locating System for Construction Safety Management. J. Comput. Civ. Eng. 2012, 11, 366-377. [CrossRef]

14. Chen, K.; Chen, W.; Li, C.T.; Cheng, J.C.P. A BIM-based location aware AR collaborative framework for facility maintenance management. J. Inf. Technol. Constr. 2019, 24, 360-380.

15. Chen, Y.-J.; Lai, Y.-S.; Lin, Y.-H. BIM-based augmented reality inspection and maintenance of fire safety equipment. Autom. Constr. 2020, 110, 103041. [CrossRef]

16. Riaz, Z.; Parn Erika, A.; Edwards David, J.; Arslan, M.; Shen, C.; Pena-Mora, F. BIM and sensor-based data management system for construction safety monitoring. J. Eng. Des. Technol. 2017, 15, 738-753. [CrossRef]

17. Wei, W.; Wang, C.; Lee, Y. BIM-Based Construction Noise Hazard Prediction and Visualization for Occupational Safety and Health Awareness Improvement. In ASCE International Workshop on Computing in Civil Engineering 2017; American Society of Civil Engineers: Reston, VA, USA, 2017; pp. 262-269. [CrossRef]

18. LeCun, Y.; Bengio, Y.; Hinton, G. Deep Learning. Nature 2015, 521, 436-444. [CrossRef] [PubMed]

19. Soltani, M.M.; Zhu, Z.; Hammad, A. Skeleton estimation of excavator by detecting its parts. Autom. Constr. 2017, 82, 1-15. [CrossRef]

20. Guo, H.; Yu, Y.; Skitmore, M. Visualization technology-based construction safety management: A review. Autom. Constr. 2017, 73, 135-144. [CrossRef]

21. Olde Scholtenhuis, L.L.; Hartmann, T.; Dorée, A.G. Comparing Mindfulness in Manual and 4D-Supported Coordination Practices. In Construction Research Congress 2014: Construction in a Global Network; American Society of Civil Engineers: Reston, VA, USA, 2014; pp. 160-168.

22. Boton, C. Supporting constructability analysis meetings with Immersive Virtual Reality-based collaborative BIM 4D simulation. Autom. Constr. 2018, 96,1-15. [CrossRef]

23. Wu, S.; Hou, L.; Zhang, G. Integrated Application of BIM and eXtended Reality Technology: A Review, Classification and Outlook. Lect. Notes Civ. Eng. 2021, 98, 1227-1236.

24. Wolfartsberger, J. Analyzing the potential of Virtual Reality for engineering design review. Autom. Constr. 2019, 104, 27-37. [CrossRef]

25. Sun, L.; Fukuda, T.; Resch, B. A synchronous distributed cloud-based virtual reality meeting system for architectural and urban design. Front. Archit. Res. 2014, 3, 348-357. [CrossRef] 
26. Joshi, S.; Hamilton, M.; Warren, R.; Faucett, D.; Tian, W.; Wang, Y.; Ma, J. Implementing Virtual Reality technology for safety training in the precast/ prestressed concrete industry. Appl. Ergon. 2021, 90, 103286. [CrossRef]

27. Goulding, J.; Nadim, W.; Petridis, P.; Alshawi, M. Construction industry offsite production: A virtual reality interactive training environment prototype. Adv. Eng. Inform. 2012, 26, 103-116. [CrossRef]

28. Davila Delgado, J.M.; Oyedele, L.; Demian, P.; Beach, T. A research agenda for augmented and virtual reality in architecture, engineering and construction. Adv. Eng. Inform. 2020, 45, 101122. [CrossRef]

29. Zhou, Y.; Luo, H.; Yang, Y. Implementation of augmented reality for segment displacement inspection during tunneling construction. Autom. Constr. 2017, 82, 112-121. [CrossRef]

30. Shin, D.H.; Dunston, P.S. Evaluation of Augmented Reality in steel column inspection. Autom. Constr. 2009, 18, 118-129. [CrossRef]

31. Qureshi, Z.H. A review of accident modelling approaches for complex socio-technical systems. In Proceedings of the twelfth Australian workshop on Safety critical systems and software and safety-related programmable systems, Adelaide, Australia, 30-31 August 2007.

32. Gibb, A.; Hide, S.; Haslam, R.; Hastings, S.; Suraji, A.; Duff, A.R.; Abdelhamid, T.S.; Everett, J.G. Identifying Root Causes of Construction Accidents. J. Constr. Eng. Manag. 2015, 127, 348-349. [CrossRef]

33. Choe, S.; Leite, F. Transforming inherent safety risk in the construction Industry: A safety risk generation and control model. Saf. Sci. 2020, 124, 104594. [CrossRef]

34. Work Health and Safety (Construction Work) Code of Practice 2015. Available online: https:/ / www.legislation.gov.au/Details/F201 6L00394 (accessed on 17 August 2020).

35. Love, P.E.D.; Teo, P.; Morrison, J. Unearthing the nature and interplay of quality and safety in construction projects: An empirical study. Saf. Sci. 2018, 103, 270-279. [CrossRef]

36. Choudhry, R.M. Behavior-based safety on construction sites: A case study. Accid. Anal. Prev. 2014, 70, 14-23. [CrossRef]

37. Wang, L.; Yuan, J.; Wu, C.; Wang, X. Practical algorithm for stochastic optimal control problem about microbial fermentation in batch culture. Optim. Lett. 2019, 13, 527-541. [CrossRef]

38. Wong, T.K.M.; Man, S.S.; Chan, A.H.S. Critical factors for the use or non-use of personal protective equipment amongst construction workers. Saf. Sci. 2020, 126, 104663. [CrossRef]

39. Chen, J.; Wang, R.Q.; Lin, Z.; Guo, X. Measuring the cognitive loads of construction safety sign designs during selective and sustained attention. Saf. Sci. 2018, 105, 9-21. [CrossRef]

40. Motamedi, A.; Wang, Z.; Yabuki, N.; Fukuda, T.; Michikawa, T. Signage visibility analysis and optimization system using BIM-enabled virtual reality (VR) environments. Adv. Eng. Inform. 2017, 32, 248-262. [CrossRef]

41. Liang, X.; Shen, G.Q.; Bu, S. Multiagent Systems in Construction: A Ten-Year Review. J. Comput. Civ. Eng. 2016, $30,04016016$. [CrossRef]

42. Mok, K.Y.; Shen, G.Q.; Yang, J. Stakeholder management studies in mega construction projects: A review and future directions. Int. J. Proj. Manag. 2015, 33, 446-457. [CrossRef]

43. Cho, C.; Kim, K.; Park, J.W.; Cho, Y.K. Data-Driven Monitoring System for Preventing the Collapse of Scaffolding Structures. J. Constr. Eng. Manag. 2018, 144. [CrossRef]

44. Abedini, M.; Zhang, C. Performance Assessment of Concrete and Steel Material Models in LS-DYNA for Enhanced Numerical Simulation, A State of the Art Review. Arch. Comput. Method E 2020. [CrossRef]

45. Zhu, L.; Kong, L.; Zhang, C. Numerical Study on Hysteretic Behaviour of Horizontal-Connection and Energy-Dissipation Structures Developed for Prefabricated Shear Walls. Appl. Sci. 2020, 10, 1240. [CrossRef]

46. Li, H.; Chen, D.; Zhang, H.; Wu, C.; Wang, X. Hamiltonian analysis of a hydro-energy generation system in the transient of sudden load increasing. Appl. Energy 2017, 185, 244-253. [CrossRef]

47. Kolar, Z.; Chen, H.; Luo, X. Transfer learning and deep convolutional neural networks for safety guardrail detection in 2D images. Autom. Constr. 2018, 89, 58-70. [CrossRef]

48. Song, Y.; Wang, X.; Wright, G.; Thatcher, D.; Wu, P.; Felix, P. Traffic Volume Prediction With Segment-Based Regression Kriging and its Implementation in Assessingthe Impact of Heavy Vehicles. IEEE Trans. Intell. Transp. Syst. 2019, 20, 232-243. [CrossRef]

49. Soltani, M.M.; Zhu, Z.; Hammad, A. Framework for Location Data Fusion and Pose Estimation of Excavators Using Stereo Vision. J. Comput. Civ. Eng. 2018, 32, 04018045. [CrossRef]

50. Kim, H.; Lee, H.-S.; Park, M.; Chung, B.; Hwang, S. Automated hazardous area identification using laborers' actual and optimal routes. Autom. Constr. 2016, 65, 21-32. [CrossRef]

51. Yang, K.; Ahn, C.R.; Vuran, M.C.; Kim, H. Collective sensing of workers' gait patterns to identify fall hazards in construction. Autom. Constr. 2017, 82, 166-178. [CrossRef]

52. Kim, H.; Kim, K.; Kim, H. Vision-Based Object-Centric Safety Assessment Using Fuzzy Inference: Monitoring Struck-By Accidents with Moving Objects. J. Comput. Civ. Eng. 2016, 30, 04015075. [CrossRef]

53. Zhou, Y.; Ding, L.Y.; Chen, L.J. Application of 4D visualization technology for safety management in metro construction. Autom. Constr. 2013, 34, 25-36. [CrossRef]

54. He, V.; Peansupap, V. Application of Sensor Technology for Warning Unsafe Conditions from Moving Objects above Construction Workers. In Proceedings of the 2018 2nd International Conference on Engineering Innovation (ICEI), Bangkok, Thailand, 5-6 July 2018; pp. 69-74. 
55. Soltanmohammadlou, N.; Sadeghi, S.; Hon, C.K.H.; Mokhtarpour-Khanghah, F. Real-time locating systems and safety in construction sites: A literature review. Saf. Sci. 2019, 117, 229-242. [CrossRef]

56. Park, M.-W.; Brilakis, I. Continuous localization of construction workers via integration of detection and tracking. Autom. Constr. 2016, 72, 129-142. [CrossRef]

57. Konstantinou, E.; Brilakis, I. Matching Construction Workers across Views for Automated 3D Vision Tracking On-Site. J. Constr. Eng. Manag. 2018, 144. [CrossRef]

58. Kim, K.; Kim, H.; Kim, H. Image-based construction hazard avoidance system using augmented reality in wearable device. Autom. Constr. 2017, 83, 390-403. [CrossRef]

59. Son, H.; Seong, H.; Choi, H.; Kim, C. Real-Time Vision-Based Warning System for Prevention of Collisions between Workers and Heavy Equipment. J. Comput. Civ. Eng. 2019, 33, 04019029. [CrossRef]

60. Zhang, P.; Li, N.; Jiang, Z.; Fang, D.; Anumba, C.J. An agent-based modeling approach for understanding the effect of workermanagement interactions on construction workers' safety-related behaviors. Autom. Constr. 2019, 97, 29-43. [CrossRef]

61. Guo, H.; Yu, Y.; Ding, Q.; Skitmore, M. Image-and-Skeleton-Based Parameterized Approach to Real-Time Identification of Construction Workers' Unsafe Behaviors. J. Constr. Eng. Manag. 2018, 144, 04018042. [CrossRef]

62. Han, S.; Lee, S. A vision-based motion capture and recognition framework for behavior-based safety management. Autom. Constr. 2013, 35, 131-141. [CrossRef]

63. Fang, W.; Zhong, B.; Zhao, N.; Love, P.E.D.; Luo, H.; Xue, J.; Xu, S. A deep learning-based approach for mitigating falls from height with computer vision: Convolutional neural network. Adv. Eng. Inform. 2019, 39, 170-177. [CrossRef]

64. Li, H.; Li, X.; Luo, X.; Siebert, J. Investigation of the causality patterns of non-helmet use behavior of construction workers. Autom. Constr. 2017, 80, 95-103. [CrossRef]

65. Park, M.W.; Elsafty, N.; Zhu, Z. Hardhat-Wearing Detection for Enhancing On-Site Safety of Construction Workers. J. Constr. Eng. Manag. 2015, 141, 04015024. [CrossRef]

66. Fang, Q.; Li, H.; Luo, X.; Ding, L.; Luo, H.; Li, C. Computer vision aided inspection on falling prevention measures for steeplejacks in an aerial environment. Autom. Constr. 2018, 93, 148-164. [CrossRef]

67. Fang, W.; Ding, L.; Luo, H.; Love, P.E.D. Falls from Heights: A Computer Vision-based Approach for Safety Harness Detection. Autom. Constr. 2018, 91, 53-61. [CrossRef]

68. Gatti, U.C.; Schneider, S.; Migliaccio, G.C. Physiological condition monitoring of construction workers. Autom. Constr. 2014, 44, 227-233. [CrossRef]

69. Umer, W.; Li, H.; Lu, W.; Szeto, G.P.Y.; Wong, A.Y.L. Development of a tool to monitor static balance of construction workers for proactive fall safety management. Autom. Constr. 2018, 94, 438-448. [CrossRef]

70. Hwang, S.; Jebelli, H.; Choi, B.; Choi, M.; Lee, S.H. Measuring Workers' Emotional State during Construction Tasks Using Wearable EEG. J. Constr. Eng. Manag. 2018, 144, 04018050. [CrossRef]

71. Jebelli, H.; Hwang, S.; Lee, S. EEG-based workers' stress recognition at construction sites. Autom. Constr. 2018, 93, 315-324. [CrossRef]

72. Alizadehsalehi, S.; Hadavi, A.; Huang, J.C. From BIM to extended reality in AEC industry. Autom. Constr. 2020, 116, 103254. [CrossRef]

73. Akram, R.; Thaheem, M.J.; Nasir, A.R.; Ali, T.H.; Khan, S. Exploring the role of building information modeling in construction safety through science mapping. Saf. Sci. 2019, 120, 456-470. [CrossRef]

74. Ding, L.; Zhou, Y.; Akinci, B. Building Information Modeling (BIM) application framework: The process of expanding from 3D to computable nD. Autom. Constr. 2014, 46, 82-93. [CrossRef]

75. Cortés-Pérez, J.P.; Cortés-Pérez, A.; Prieto-Muriel, P. BIM-integrated management of occupational hazards in building construction and maintenance. Autom. Constr. 2020, 113, 103115. [CrossRef]

76. Zhang, S.; Teizer, J.; Lee, J.-K.; Eastman, C.M.; Venugopal, M. Building Information Modeling (BIM) and Safety: Automatic Safety Checking of Construction Models and Schedules. Autom. Constr. 2013, 29, 183-195. [CrossRef]

77. Getuli, V.; Ventura, S.M.; Capone, P.; Ciribini, A.L. BIM-based Code Checking for Construction Health and Safety. Procedia Eng. 2017, 196, 454-461. [CrossRef]

78. Xing, X.; Zhong, B.; Luo, H.; Li, H.; Wu, H. Ontology for safety risk identification in metro construction. Comput. Ind. 2019, 109, 14-30. [CrossRef]

79. Lu, Y.; Li, Q.; Zhou, Z.; Deng, Y. Ontology-based knowledge modeling for automated construction safety checking. Saf. Sci. 2015, 79, 11-18. [CrossRef]

80. Zhang, C.; Alam, Z.; Sun, L.; Su, Z.; Samaliet, B. Fibre Bragg grating sensor-based damage response monitoring of an asymmetric reinforced concrete shear wall structure subjected to progressive seismic loads. Struct. Control HLTH 2019, 26, 2307. [CrossRef]

81. Alam, Z.; Sun, L.; Zhang, C.; Su, Z.; Samali, B. Experimental and numerical investigation on the complex behaviour of the localised seismic response in a multi-storey plan-asymmetric structure. Struct. Infrastruct E 2020, 1-17. [CrossRef]

82. Zhang, C.; Gholipour, G.; Mousavi, A.A. Blast loads induced responses of RC structural members: State-of-the-art review. Compos. Part B Eng. 2020, 195, 108066. [CrossRef]

83. Zhang, C.; Gholipour, G.; Mousavi, A.A. Nonlinear dynamic behavior of simply-supported RC beams subjected to combined impact-blast loading. Eng. Struct. 2019, 181, 124-142. [CrossRef] 
84. Zhang, C.; Gholipour, G.; Mousavi, A.A. State-of-the-art review on responses of RC structures subjected to lateral impact loads. Arch. Comput. Method. E 2020, 8. [CrossRef]

85. Zhang, C.; Abedini, M.; Mehrmashhadi, J. Development of pressure-impulse models and residual capacity assessment of RC columns using high fidelity Arbitrary Lagrangian-Eulerian simulation. Eng. Struct. 2020, 224, 111219. [CrossRef]

86. Li, H.; Lu, M.; Chan, G.; Skitmore, M. Proactive training system for safe and efficient precast installation. Autom. Constr. 2015, 49, 163-174. [CrossRef]

87. Heng, L.; Shuang, D.; Skitmore, M.; Qinghua, H.; Qin, Y. Intrusion warning and assessment method for site safety enhancement. Saf. Sci. 2016, 84, 97-107. [CrossRef]

88. Lee, G.; Cho, J.; Ham, S.; Lee, T.; Lee, G.; Yun, S.H.; Yang, H.J. A BIM- and sensor-based tower crane navigation system for blind lifts. Autom. Constr. 2012, 26, 1-10. [CrossRef]

89. Talmaki, S.A.; Dong, S.; Kamat, V.R. Geospatial Databases and Augmented Reality visualization for improving safety in urban excavation operations. In Construction Research Congress 2010: Innovation for Reshaping Construction Practice; ASCE: Reston, VA, USA, 2010; pp. 91-101.

90. Pedro, A.; Le, Q.T.; Park, C.S. Framework for Integrating Safety into Construction Methods Education through Interactive Virtual Reality. J. Prof. Issues Eng. Educ. Pract. 2016, 142, 04015011. [CrossRef]

91. Wang, X.; Dunston, P.S. A user-centered taxonomy for specifying mixed reality systems for aec industry. Electron. J. Inf. Technol. Constr. 2011, 16, 493-508.

92. Li, H.; Chan, G.; Skitmore, M. Visualizing safety assessment by integrating the use of game technology. Autom. Constr. 2012, 22, 498-505. [CrossRef]

93. Guo, H.; Li, H.; Chan, G.; Skitmore, M. Using game technologies to improve the safety of construction plant operations. Accid. Anal. Prev. 2012, 48, 204-213. [CrossRef] [PubMed]

94. Li, X.; Yi, W.; Chi, H.-L.; Wang, X.; Chan, A.P.C. A critical review of virtual and augmented reality (VR/AR) applications in construction safety. Autom. Constr. 2018, 86, 150-162. [CrossRef]

95. Le, Q.T.; Pedro, A.; Park, C.S. A Social Virtual Reality Based Construction Safety Education System for Experiential Learning. J. Intell. Robot. Syst. 2015, 79, 487-506. [CrossRef]

96. Shi, Y.; Du, J.; Ahn, C.R.; Ragan, E. Impact assessment of reinforced learning methods on construction workers' fall risk behavior using virtual reality. Autom. Constr. 2019, 104, 197-214. [CrossRef]

97. Lin, K.Y.; Son, J.W.; Rojas, E.M. A pilot study of a 3D game environment for construction safety education. Electron. J. Inf. Technol. Constr. 2011, 16, 69-83.

98. Li, C.T.; Cheng, J.C.P.; Chen, K. Top 10 technologies for indoor positioning on construction sites. Autom. Constr. 2020, 118, 103309. [CrossRef]

99. Xiao, B.; Zhu, Z. Two-Dimensional Visual Tracking in Construction Scenarios: A Comparative Study. J. Comput. Civ. Eng. 2018, 32, 04018006. [CrossRef]

100. Zhang, C.; Wang, H. Swing Vibration Control of Suspended Structure Using Active Rotary Inertia Driver System: Parametric Analysis and Experimental Verification. Appl. Sci. 2019, 9, 3144. [CrossRef]

101. Jin, Y.; Xie, L.; Yang, H. Locally upper bounded poset-valued maps and stratifiable spaces. Topol. Appl. 2020, 107517. [CrossRef]

102. Dong, Q.; Cui, L.; Si, S. Reliability and availability analysis of stochastic degradation systems based on bivariate Wiener processes. Appl. Math. Model. 2020, 79, 414-433. [CrossRef]

103. Graham, K.; Pybus, C.; Arellano, N.; Doherty, J.; Chow, L.; Fai, S.; Grunt, T. Defining Geometry Levels for Optimizing BIM for VR: Insights from Traditional Architectural Media. Technol. Archit. Des. 2019, 3, 234-244. [CrossRef]

104. Osello, A.; Lucibello, G.; Morgagni, F. HBIM and Virtual Tools: A New Chance to Preserve Architectural Heritage. Buildings 2018, 8, 12. [CrossRef]

105. Qu, X.; Yu, Y.; Zhou, M.; Lin, C.; Wang, X. Jointly dampening traffic oscillations and improving energy consumption with electric, connected andautomated vehicles: A reinforcement learning basedapproach. Appl. Energy 2020, 257, 114030. [CrossRef]

106. Wu, P.; Wang, J.; Wang, X. A critical review of the use of 3-D printing in the construction industry. Autom. Constr. 2016, 68, 21-31. [CrossRef]

107. Getuli, V.; Capone, P.; Bruttini, A.; Isaac, S. BIM-based immersive Virtual Reality for construction workspace planning: A safetyoriented approach. Autom. Constr. 2020, 114, 103160. [CrossRef]

108. Wu, W.; Yang, H.; Chew, D.A.S.; Yang, S.-h.; Gibb, A.G.F.; Li, Q. Towards an autonomous real-time tracking system of near-miss accidents on construction sites. Autom. Constr. 2010, 19, 134-141. [CrossRef]

109. Golovina, O.; Teizer, J.; Pradhananga, N. Heat map generation for predictive safety planning: Preventing struck-by and near miss interactions between workers-on-foot and construction equipment. Autom. Constr. 2016, 71, 99-115. [CrossRef]

110. Fang, D.; Zhao, C.; Zhang, M. A Cognitive Model of Construction Workers' Unsafe Behaviors. J. Constr. Eng. Manag. 2016, 142, 04016039. [CrossRef]

111. Chang, Y.H.J.; Mosleh, A. Cognitive modeling and dynamic probabilistic simulation of operating crew response to complex system accidents. Part 2: IDAC performance influencing factors model. Reliab. Eng. Syst. Saf. 2007, 92, 1014-1040. [CrossRef]

112. Zhang, M.; Fang, D. A cognitive analysis of why Chinese scaffolders do not use safety harnesses in construction. Constr. Manag. Econ. 2013, 31, 207-222. [CrossRef] 
113. El Ammari, K.; Hammad, A. Remote interactive collaboration in facilities management using BIM-based mixed reality. Autom. Constr. 2019, 107, 102940. [CrossRef]

114. Chen, Y.C.; Chi, H.L.; Kang, S.C.; Hsieh, S.H. Attention-Based User Interface Design for a Tele-Operated Crane. J. Comput. Civ. Eng. 2016, 30, 04015030. [CrossRef]

115. Lee, S.; Akin, O. Augmented reality-based computational fieldwork support for equipment operations and maintenance. Autom. Constr. 2011, 20, 338-352. [CrossRef]

116. Wang, T.K.; Piao, Y. Development of BIM-AR-Based Facility Risk Assessment and Maintenance System. J. Perform. Constr. Facil. 2019, 33, 04019068. [CrossRef]

117. Diao, P.H.; Shih, N.J. BIM-Based AR Maintenance System (BARMS) as an Intelligent Instruction Platform for Complex Plumbing Facilities. Appl. Sci. 2019, 9, 1592. [CrossRef]

118. Cristina, P.; Sergio, C.; Jesús, G.; Marcos, F.; Montse, P. From the Paper to the Tablet: On the Design of an AR-Based Tool for the Inspection of Pre-Fab Buildings. Preliminary Results of the SIRAE Project. Sensors 2018, 18, 1262.

119. Fang, W.; Love, P.E.D.; Luo, H.; Ding, L. Computer vision for behaviour-based safety in construction: A review and future directions. Adv. Eng. Inform. 2020, 43, 100980. [CrossRef] 